NOTA CIENTÍFICA

\title{
INDUÇÃO DE EMBRIÕES SOMÁTICOS GLOBULARES E CORDIFORMES DE CAFEEIRO POR BAP E SACAROSE ${ }^{1}$
}

\section{GLOBULAR AND CORDIFORM COFFEE SOMATIC EMBRYOS INDUCED BY BAPE SUCROSE}

\author{
Alba Regina PEREIRA ${ }^{2}$ \\ Moacir PASQUAL ${ }^{3 *}$ \\ Edvan Alves CHAGAS ${ }^{4}$ \\ Chrystiane Borges FRÁGUAS ${ }^{4}$ \\ Leonardo Ferreira DUTRA ${ }^{5}$
}

\begin{abstract}
RESUMO
Os programas convencionais de melhoramento de cafeeiro requerem um período longo para obtenção de novas cultivares. Uma alternativa para minimizar tal problema é a utilização das técnicas de cultura de tecidos. Objetivou-se estudar o efeito de BAPe sacarose na embriogênese somática de cafeeiro. Calos de Coffea arabica L. cv. Acaiá Cerrado foram inoculados em tubos de ensaio, contendo $15 \mathrm{ml}$ do meio de cultura semi-sólido 'R' de regeneração. Os tratamentos consistiram de combinação de diferentes concentrações de $\operatorname{BAP}\left(0,2,4,6\right.$ e $\left.8 \mathrm{mg} \cdot \mathrm{L}^{-1}\right)$ e sacarose $\left(0,15,30\right.$ e $\left.60 \mathrm{~g} \cdot \mathrm{L}^{-1}\right)$, acrescido de $7 \mathrm{~g} \cdot \mathrm{L}^{-1}$ de ágar e pH ajustado para 5,8 , antes da autoclavagem a $121^{\circ} \mathrm{C}$ e $1,5 \mathrm{~atm}$ por 20 minutos. A inoculação foi realizada em câmara de fluxo laminar e os calos foram mantidos em sala de crescimento com temperatura de $27 \pm 1^{\circ} \mathrm{C}$, fotoperíodo de 16 horas e $32 \mathrm{mM} . \mathrm{m}^{-2} . \mathrm{s}^{-1}$ de intensidade luminosa. Maior número de embriões globulares e cordiformes foi obtido utilizando-se $8 \mathrm{mg} \cdot \mathrm{L}^{-1}$ de BAP associado a $60 \mathrm{mg} \cdot \mathrm{L}^{-1}$ de sacarose, proporcionando um total de 247 e 182 embriões por explante, respectivamente.
\end{abstract}

Palavras-chave: Coffea arabica, embriogênese somática, BAP, carboidrato

\footnotetext{
ABSTRACT

The conventional breeding programs for coffee plants require a long period for obtaining new cultivars. Techniques of tissue culture are used to minimize such problem. The effect of BAP and sucrose in somatic embryogenesis of coffee plants was evaluated. Calli of Coffea arabica L. 'Acaiá Cerrado' were inoculated in test tubes containing $15 \mathrm{ml}$ of a ' $\mathrm{R}$ ' regeneration semi-solid culture medium. The treatments consisted of different BAP concentrations $\left(0,2,4,6\right.$ and $\left.8 \mathrm{mg}_{\mathrm{L}} \mathrm{L}^{-1}\right)$ and sucrose $\left(0,15,30\right.$ and $\left.60 \mathrm{~g} \cdot \mathrm{L}^{-1}\right)$, and the culture medium was supplemented with $7 \mathrm{~g} \cdot \mathrm{L}^{-1}$ agar. The $\mathrm{pH}$ was adjusted to 5.8 before being sterilized at $121^{\circ} \mathrm{C}$ and 1.5 atm for 20 minutes. The calli were inoculated in test tubes in laminar flow chamber and the cultures were kept in a growth room at $27 \pm 1{ }^{\circ} \mathrm{C}, 16$-hour photoperiod and $32 \mathrm{mM} \cdot \mathrm{m}^{-2} . \mathrm{s}^{-1}$ light intensity. The highest number of globular and cordiform embryos were obtained by using $8 \mathrm{mg} . \mathrm{L}^{-1}$ of BAP combined to $60{\mathrm{mg} . \mathrm{L}^{-1}}^{-}$sucrose which provided a total of 247 and 182 embryos per explant, respectively.

Key-words: Coffea arabica, somatic embryogenesis, BAP, carbohydrate.

${ }^{1}$ Suporte financeiro do CBP\&D Café e FAPEMIG;

${ }^{2}$ Aluna de graduação (Bolsista - PIBIC/CNPq);

${ }^{3}$ Depto de Agricultura/UFLA, Lab. Cultura de tecidos. Campus Universitário, C.P. 37, CEP 37200-000 Lavras-MG. *Autor correspondente mpasqual@ufla.br;

${ }^{4}$ Mestrando em Fitotecnia/CAPES

${ }^{5}$ Bolsista Recém-Doutor/CNPq.
} 


\section{INTRODUÇÃO}

A hibridação e a seleção de germoplasma de Coffea arabica requerem um período longo, aproximadamente 30 anos, para se dispor de uma nova cultivar. Além disso, a multiplicação assexual pelos métodos tradicionais restringi-se à utilização de fragmentos de ramos ortotrópicos, que são limitados em clones recentemente selecionados (4).

As dificuldades de multiplicação podem ser minimizadas por meio do cultivo in vitro, possibilitando a propagação de material selecionado em larga escala e em curto espaço de tempo, aspectos importantes para as culturas de ciclo longo como o cafeeiro (1).

Uma das técnicas de cultivo in vitro é a embriogênese somática, caracterizada pelo desenvolvimento de embriões a partir de células somáticas, onde o embrião somático é morfológica e fisiologicamente similar ao embrião zigótico (10). O surgimento dos primeiros embriões, a taxa de embriogênese e o número de embriões produzidos por explante dependem, entre outros fatores, das combinações de auxina/ citocinina utilizadas na etapa de indução, da duração desta, origem do explante e estado fisiológico da planta matriz (5).

A embriogênese somática indireta requer a determinação de células diferenciadas, a proliferação de calos e a indução de células embriogênicas determinadas, dependendo da ação de reguladores de crescimento para a retomada da atividade mitótica e determinação do estádio embriogênico $(9,10)$.

Embriões somáticos foram obtidos a partir de calos embriogênicos friáveis cultivados em meio secundário contendo apenas BAP (2). Maciel (8), trabalhando com as cvs. Catuaí Amarelo e Tupi, obteve uma média de 15 embriões/explante quando foram acrescentados $2 \mathrm{mg} \cdot \mathrm{L}^{-1}$ de BAP ao meio de cultura.

A sacarose tem sido a fonte de carboidratos mais usada na embriogênese somática, embora outros mono e dissacarídeos possam ser utilizados sendo que sua concentração influencia nos processos de iniciação e de diferenciação dos embriões. A utilização de $30 \mathrm{~g} \cdot \mathrm{L}^{-1}$ de sacarose ao meio de cultura promoveu uma média de $202 \mathrm{em}$ briões globulares e cordiformes até o nível máximo de $3,3 \mathrm{mg} \cdot \mathrm{L}^{-1}$ de BAP, com redução na presença de concentrações mais elevadas (8). No entanto, para embriões cotiledonares os melhores resultados foram alcançados utilizando-se $45 \mathrm{~g} . \mathrm{L}^{-1}$ de sacarose combinados com $2 \mathrm{mg} \cdot \mathrm{L}^{-1}$ da citocinina BAP.

No presente trabalho, objetivou-se estudar a formação de embriões somáticos em cafeeiro em resposta a diferentes concentrações de BAP e sacarose no meio de cultura.

\section{MATERIAL E MÉTODOS}

Utilizaram-se calos de Coffea arabica L. cv. Acaiá Cerrado, oriundos de folhas, estabelecidos in vitro a cerca de nove meses, induzidos com uso de 2iP e das auxinas AIB, 2,4D e ANA. Esses calos foram inoculados assepticamente em tubos de ensaio (25 $\mathrm{x}$ $150 \mathrm{~mm}$ ), contendo $15 \mathrm{ml}$ do meio de cultura semisólido ' $R$ ' de regeneração (3). Os tratamentos consistiram de combinação entre diferentes concentrações de $\operatorname{BAP}\left(0,2,4,6\right.$ e $\left.8 \mathrm{mg}^{-1} \mathrm{~L}^{-1}\right)$ e sacarose $(0,15,30 \mathrm{e}$ 60 g. $\left.\mathrm{L}^{-1}\right)$ adicionados ao meio ' $R$ ' de regeneração, acrescido de 7 g.L-1 de ágar, pH ajustado para 5,8 antes da autoclavagem a $121^{\circ} \mathrm{C}$ e $1,5 \mathrm{~atm}$ por 20 minutos. A inoculação foi realizada em câmara de fluxo laminar e os calos, após inoculação, foram mantidos em sala de crescimento com temperatura de 27 $\pm 1^{\circ} \mathrm{C}$, fotoperíodo de 16 horas e $32 \mu \mathrm{mol} . \mathrm{m}^{-2} . \mathrm{s}^{-1} \mathrm{de}$ intensidade luminosa. $O$ delineamento experimental foi inteiramente casualizado em esquema fatorial $5 \mathrm{x}$ 4 , com quatro repetições e três tubos por parcela, cada tubo contendo um explante. Após 90 dias em sala de crescimento quantificou-se o número de embriões formados. Para a análise estatística, utilizouse o software Sisvar (6), e os tratamentos comparados através de regressão polinomial.

\section{RESULTADOS E DISCUSSÃO}

Maior número de embriões globulares foi obtido utilizando-se $8 \mathrm{mg} \cdot \mathrm{L}^{-1}$ de BAP associada a $60 \mathrm{~g} \cdot \mathrm{L}^{-}$ 1 de sacarose, proporcionando um total de 247 embriões formados (Figura 1). Essa concentração de BAP foi efetiva quando adicionada ao meio de cultura mesmo em altas concentrações de sacarose, provavelmente compensando o alto potencial osmótico ocasionado pela adição desse carboidrato.

A ausência e a menor concentração de BAP (2 $\left.\mathrm{mg} . \mathrm{L}^{-1}\right)$ proporcionaram a formação de menor quantidade de embriões globulares, independente da concentração de sacarose utilizada. Quando utilizaramse concentrações de 4 e $6 \mathrm{mg} . \mathrm{L}^{-1}$ de BAP, houve um incremento na formação de embriões na medida em que a concentração de sacarose foi elevada até 31,06 e 27,85 g.L - $^{-1}$ (170 e 122 embriões, respectivamente), a partir das quais houve redução no número de embriões formados. Esse resultado foi provavelmente devido a uma elevação no potencial osmótico do meio de cultura.

Pode-se constatar a essencialidade da citocinina BAP na embriogênese somática de cafeeiro, concordando com os resultados apresentados por Berthouly e Etienne (2), que obtiveram formação de embriões somáticos a partir de calos embriogênicos cultivados na presença de BAP. A embriogênese somática indireta é dependente da ação de reguladores de crescimento para a retomada da atividade mitótica e determinação do estádio embriogênico $(9,10)$. 
PEREIRA, A.R. et al. Indução de embriões somáticos...

O grande número de embriões globulares formados com alta concentração de sacarose, corrobora a importância da utilização de uma fonte de carboidrato no meio de cultura. A sacarose influencia diretamente nos processos de iniciação e diferenciação dos embriões somáticos (7). Maciel (8) induzindo embriogênese somática indireta em cafeeiro 'Obatã' a partir de calos, observou a maior formação de embriões globulares e torpedo em meio de cultura acrescido de $30 \mathrm{~g} \cdot \mathrm{L}^{-1}$ de sacarose e 3,3 e $3 \mathrm{mg} \cdot \mathrm{L}^{-1}$ de BAP, respectivamente.

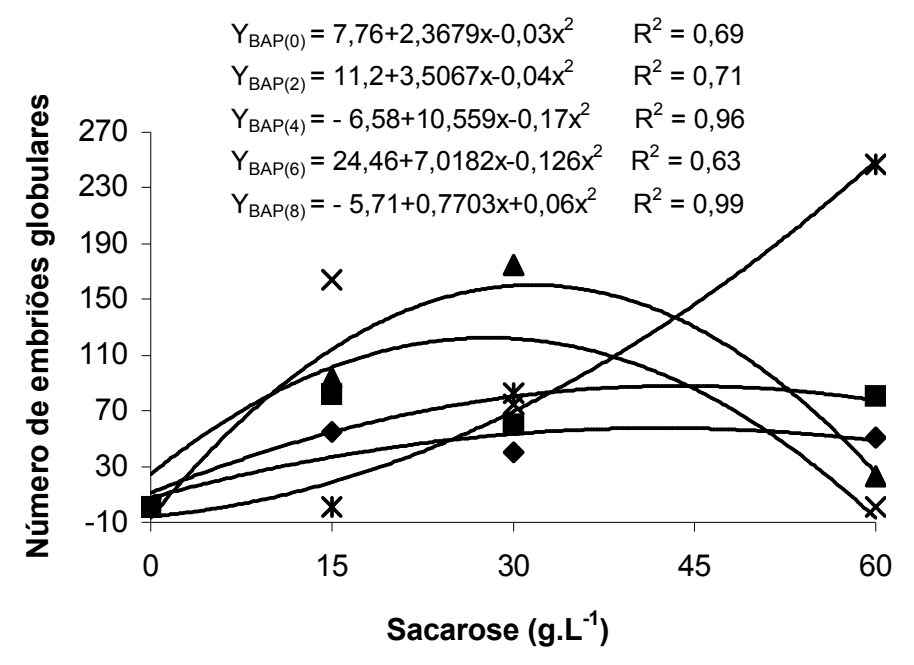

$\diamond 0 \mathrm{mg} \cdot \mathrm{L}^{-1} \quad \mathbf{\square} \mathrm{mg} \cdot \mathrm{L}^{-1} \Delta 4 \mathrm{mg} \cdot \mathrm{L}^{-1} \times 6 \mathrm{mg} \cdot \mathrm{L}^{-1} \approx 8 \mathrm{mg} \cdot \mathrm{L}^{-1}$

FIGURA 1 - Número de embriões globulares, formados a partir de calos de cafeeiro 'Acaiá Cerrado', em diferentes concentrações de BAP e sacarose.

Maior número de embriões cordiformes (182) foi obtido com a utilização de $60 \mathrm{~g} \cdot \mathrm{L}^{-1}$ de sacarose combinada com 8 mg. $\mathrm{L}^{-1}$ da citocinina BAP (Figura 2). Entretanto, quando se utilizaram concentrações de 2, 4 e 6 mg. $\mathrm{L}^{-1}$ de BAP, houve aumento no número de embriões formados até um máximo de 33,5, 31,8 e $30,8 \mathrm{~g} . \mathrm{L}^{-1}$ de sacarose, respectivamente, apresentando queda acentuada em concentrações mais elevadas. O maior número de embriões no estádio torpedo (202) foi obtido para a cv. Obatã quando cultivado em meio de regeneração acrescido de $3 \mathrm{mg} \cdot \mathrm{L}^{-1}$ de BAP e $30 \mathrm{~g} \cdot \mathrm{L}^{-1}$ de sacarose (8).

Não houve formação de embriões cordiformes quando estes foram cultivados em meio de cultura na ausência de sacarose e BAP, mostrando a importância da sua utilização no meio de cultura com vistas à embriogênese somática. Vários trabalhos têm de- monstrado os efeitos da concentração e tipo de carboidrato na embriogênese somática. A sacarose é o carboidrato mais utilizado e sua concentração influencia nos processos de iniciação e diferenciação dos embriões somáticos (7).

O possível aumento no potencial osmótico do meio, ocasionado pela adição de sacarose, influencia tanto no efeito da citocinina (BAP) como também na disponibilidade de nutrientes e água, limitando consequentemente a difusão destes para o explante e, afeta consequentemente a quantidade de embriões formados quando da presença de baixas concentrações de BAP. Entretanto, mesmo com elevado potencial osmótico do meio de cultura, ocasionado pela adição de $60 \mathrm{~g} \cdot \mathrm{L}^{-1}$ de sacarose, a utilização de $8 \mathrm{mg} \cdot \mathrm{L}^{-1}$ de BAP foi suficiente para superar esse efeito. 
PEREIRA, A.R. et al. Indução de embriões somáticos...

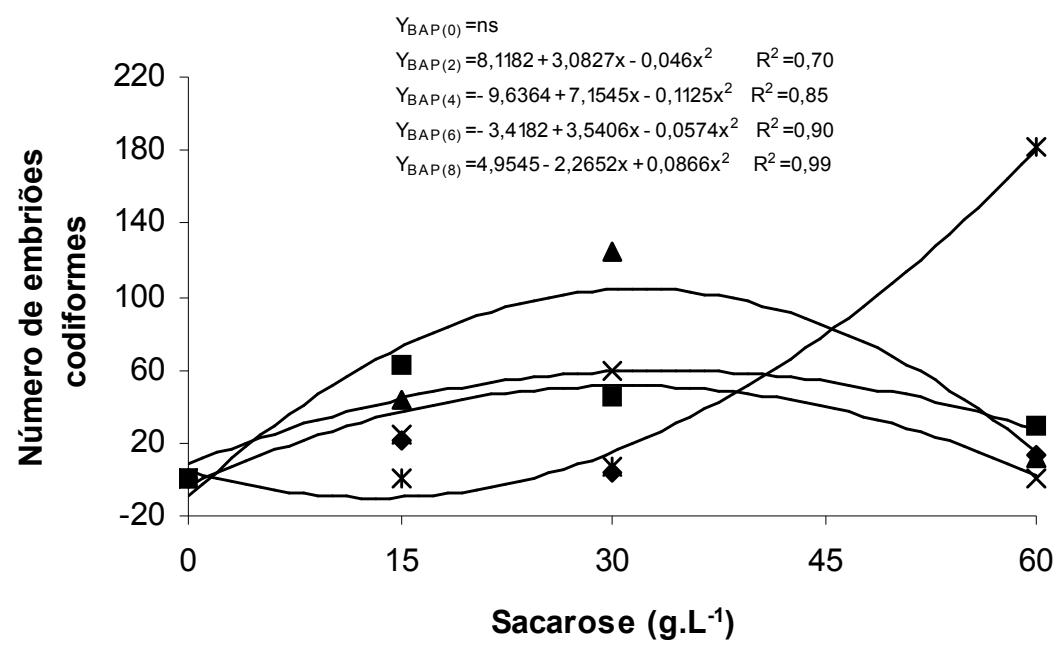

- $0 \mathrm{mg} \cdot \mathrm{L}^{-1} \quad 2 \mathrm{mg} \cdot \mathrm{L}^{-1} \triangle 4 \mathrm{mg} \cdot \mathrm{L}^{-1} \times 6 \mathrm{mg} \cdot \mathrm{L}^{-1} \approx 8 \mathrm{mg} \cdot \mathrm{L}^{-1}$

FIGURA2 - Número de embriões cordiformes formados a partir de calos de cafeeiro 'Acaiá Cerrado', em diferentes concentrações de BAP e sacarose.

É importante ressaltar que, mesmo que os maiores números de embriões globulares e cordiformes de cafeeiro tenham sido obtidos quando calos foram cultivados em meio ' $R$ ' de regeneração com $8 \mathrm{mg} . \mathrm{L}^{-1}$ de BAP associado com $60 \mathrm{~g} \cdot \mathrm{L}^{-1}$ de sacarose, houve tendência de aumento nessas variáveis em função de maiores concentrações de sacarose e BAP. Desta forma, pode-se inferir que concentrações ainda maiores destes componentes, podem proporcionar resultados superiores aos observados.

\section{REFERÊNCIAS BIBLIOGRÁFICAS}

1. ANDRADE, L.M. da C. Otimização de técnicas de cultura de tecidos para o cafeeiro (Coffea arabica L.). Lavras: UFLA, 1998. 86p. (Dissertação - Mestrado em Fitotecnia).

2. BETHOULY, M.; ETIENNE, H. Somatic embryogenesis of Coffea (Ed.) In: SERA, T.; SOCCOL, C.R.; PANDEY, A.; ROUSSOS, S. Coffe Biotechnology and Quality. Londrina: SIBAC, 2000. v.1, p.71-90.

3. BERTHOULY, M.; MICHAUX-FERRIERE, N.M. High frequency somatic embryogenesis from Coffea canephora. Plant Cell, Tissue and Organ Culture, Dordrecht, v.44, n.2, p.169-176. 1996.

4. DUBLIN, P. Tequiniques de reproduction vegétative "in vitro" et amelioration genétique chez les cafélers cultives. Café, Cacao, Thé, Paris, v.28, n.4, p.231-244, 1984.

5. DUBLIN, P. Multiplicación vegetativa de café, hevea e cacao. In ROCA, N.M.; MROGINSKI, L.A., eds. Cultivo de Tejidos en la Agricultura, Fundamentos e Aplicaciones. Turrialba, p.612-642, 1991.

6. FERREIRA, D.F. Análises estatísticas por meio do Sisvar para Windows versão 4.0. In: REUNIÃO ANUAL DA REGIÃO BRASILEIRA DA SOCIEDADE INTERNACIONAL DE BIOMETRIA, 45, 2000, São Carlos. Anais. São Carlos, UFSCar, 2000. p.255258.

7. GUERRA, M.P.; TORRES, A.C.; TEIXEIRA, J.B. Embriogênese somática e sementes sintéticas. In: TORRES, A.C.; CALDAS, L.S.; BUSO, J.A. (eds). Cultura de tecidos e transformação genética de plantas. Brasília: EMBRAPA-SPI/EMBRAPA$\mathrm{CNPH}, 1999$. p.533-568.

8. MACIEL, A.L. de R. Embriogênese somática indireta em Coffea arabica L. Lavras: UFLA, 2001. 60p. (Dissertação - Mestrado em Fitotecnia).

9. 9.SONDHAL, M.R.; NAKAMURA, T.; SHARP, W.R. Propagation of Coffea. In: HENKE, R.R.; HUGHES, K.W.; CONSTANTIN, M.P.; HOLLAENDER, A. (eds.) Tissue Culture in Forestry and Agriculture. New York: Plenum, 1985. p.215-232.

10. 10.WILLIAMS, E.G.; MAHESWARAN, G. Somatic embryogenesis: factors influencing coordinated behavior of cells as an embryogenic group. Annals of Botany, London, v.57, n.3, p.443-462, 1986. 